\title{
OPTIMALISASI DAN ARAH PENGEMBANGAN LABORATORIUM ANATOMI, FISIOLOGI DAN HISTOLOGI FIK-UNY
}

\author{
Oleh: Moch. Noerhadi \\ Dosen Jurusan Pendidikan Kesehatan dan Rekreasi FIK-UNY
}

\begin{abstract}
Abstrak
Penelitian ini bertujuan untuk mengetahui persepsi dosen dan mahasiswa tentang tingkat penggunaan, cara meningkatkan penggunaan (optimalisasi) dan arah pengembangan laboratorium anatomi, fisiologi dan histologi FIK UNY.

Populasi penelitian ini adalah seluruh mahasiswa semester ganjil yang mengambil mata kuliah Anatomi, Fisiologi dan Histologi. Jumlah sampel didasarkan pada saturasi tema pada focus group discussion maupun in-depth interview. Pemilihan sampel pada mahasiswa dilakukan berdasarkan teknik convenience sampling, sedangkan pada in-depth interview dengan pengelola laboratorium dengan mempergunakan teknik criterion sampling. Pengelola laboratorium yang diwawancarai adalah kepala laboratorium dan tekniksi laboratorium yang dianggap berperan dalam menentukan arah perkembangan laboratorium.

Berdasarkan hasil penelitian yang telah dilakukan diperoleh hasil bahwa mata kuliah dan praktikum Anatomi, Fisiologi dan Histologi sangat bermanfaat bagi mahasiswa. Walaupun sebagian mahasiswa masih mengalami kesulitan untuk memahami materi kuliah dan praktikum dikarenakan bekal yang didapat dirasakan belum mencukupi. Hal yang dikeluhkan mahasiswa adalah manajemen alat-alat Anatomi, Fisiologi dan Histologi belum terorganisir dengan baik. Pengelola laboratorium juga merasakan adanya kendala pada fasilitas-fasilitas yang ada, terutama disebabkan oleh jumlah mahasiswa yang terus bertambah, sedangkan fasilitas yang dimiliki tidak mengalami peningkatan yang berarti.
\end{abstract}

Kata kunci: optimalisasi dan pengembangan laboratorium

Fakultas Ilmu Keolahragaan (FIK), Universitas Negeri Yogyakarta memiliki tiga jurusan keilmuan, yaitu: (1) Pendidikan Kesehatan dan Rekreasi (PKR), (2) Pendidikan Kepelatihan (PKL), dan (3) Pendidikan Jasmani Kesehatan dan Rekreasi (PJKR). Jurusan PKR menitik beratkan pada kajian keilmuan olahraga pada bidang terapi, adaptif dan kebugaran jasmani. Jurusan PKL memfokuskan diri pada kepelatihan olahraga, sedangkan jurusan PJKR mengkaji tentang pendidikan jasmani di sekolah. 
Walaupun terdapat perbedaan fokus antara ketiga jurusan tersebut, semua mahasiswa pada ketiga jurusan tersebut harus memiliki dasar-dasar pemahaman tentang aspek biologis, psikologis dan interaksi sosial manusia, yang merupakan objek dari ilmunya.

Dari sisi biologis, beberapa mata kuliah rumpun biologi telah ditetapkan menjadi mata kuliah wajib tingkat fakultas yang diantaranya adalah anatomi, fisiologi dan histologi. Anatomi dan histologi mempelajari struktur makroskopis dan mikroskopis manusia, sedangkan fisiologi mempelajari fungsi dari struktur-struktur tersebut. Lebih lanjut, di FIK ketiga mata kuliah tersebut dikembangkan untuk mempelajari hubungan yang dinamis antara olahraga dengan struktur dan fungsi tubuh manusia. Pengembangan tersebut sangat diperlukan mengingat adanya kebutuhan mahasiswa FIK agar mata kuliah anatomi, fisiologi dan histologi dapat menjadi mata kuliah yang aplikatif dan kontekstual. Pada mahasiswa FIK yang menempuh jenjang strata satu (SI), mata kuliah tersebut diharapkan dapat menjawab hubungan yang dinamis antara olahraga dari kedua arah yakni: (1) pengaruh olahraga terhadap struktur dan fungsi tubuh dan (2) ciri-ciri struktur dan kapasitas fungsional yang optimal bagi olahragawan untuk berprestasi. Pada mahasiswa jurusan PKR, ketiga ilmu ini akan sangat mendasari kajian olahraga terapi, olahraga kebugaran serta olahraga adaptif.

Ketiga mata kuliah, yaitu: (1) olahraga terapi, (2) olahraga kebugaran, dan (3) olahraga adaptif di FIK UNY sudah memiliki wadah untuk pengembangannya yang berupa laboratorium anatomi, fisiologi, dan histologi. Fokus sasaran pengembangan awal yang sudah dilakukan pada kesemua laboratorium tersebut adalah pengembangan teknik pembelajaran. Sasaran tersebut diutamakan dengan tujuan optimalisasi sarana dan prasarana yang dimiliki, agar seluas-luasnya dapat diakses dan dimanfaatkan oleh mahasiswa bagi pengembangan dirinya. Fokus selanjutnya yang berupa pengembangan keilmuan anatomi, fisiologi dan histologi olahraga, belum dikerjakan secara maksimal karena terkendala dengan keterbatasan sumber daya manusia serta keterbatasan dukungan fasilitas pengembangan keilmuan. Secara garis besar, dikatakan bahwa laboratorium di FIK UNY dewasa ini masih berada di peringkat menengah dibandingkan dengan FIK di seluruh Indonesia sehingga diperlukan upaya-upaya untuk pengembangannya. (http:// www.suaramerdeka. com/harian/0312/31/ora7.htm)

Penelitian ini merupakan penelitian kualitatif yang merupakan bagian dari dukungan pada proses pengembangan laboratorium anatomi, fisiologi, dan histologi dengan jalan membantu memberikan evaluasi diri tentang usaha optimalisasi fasilitas laboratorium yang selama ini telah dikerjakan. Penelitian ini akan mengeksplorasi tentang persepsi mahasiswa dan dosen tentang tingkat optimalisasi fasilitas laboratorium dan arah pengembangan yang mereka butuhkan. Optimalisasi serta pengembangan laboratorium anatomi fisiologi dan histologi ini merupakan sasaran akhir yang ingin diupayakan dalam penelitian ini. Pada akhirnya optimalisasi dan pengembangan laboratorium ilmu biologi dasar di FIK UNY diharapkan dapat meningkatkan kualitas proses pembelajaran serta kajian keilmuan yang bermanfaat bagi pengembangan diri mahasiswa maupun staf pengajar. 
Ilmu keolahragaan merupakan disiplin ilmu yang mengembangkan prinsip dan teknik dasar untuk meningkatkan performa olahraga. Dalam pengembangannya, ilmu keolahragaan menerapkan ilmu-ilmu dasar seperti anatomi, histologi, fisiologi, kinesiologi, biomekanika, biokimia, psikologi, antropologi dan sosiologi. Bersama dengan ilmu dasar gerak, ilmu-ilmu tersebut diramu untuk mencapai tujuan meningkatkan kapasitas fisik seseorang. Melalui pendekatan tersebut seseorang dapat mengembangkan pemahaman tentang bagaimana respon dan adaptasi tubuh manusia terhadap olahraga dan pelatihan pada berbagai lingkungan dan keadaan. Kurikulum FIK UNY antara lain bertujuan untuk mempersiapkan ahli dalam bidang olahraga sesuai dengan bidang ilmu yang dijadikan konsentrasi atau keahlian di FIK UNY.

FIK UNY adalah salah satu lembaga pendidikan tinggi yang berkemampuan untuk dapat mengembangkan IPTEKS di bidang Pendidikan Jasmani, Kepelatihan Olahraga dan Ilmu Keolahragaan. Wadah utama untuk mempelajari serta mengembangkan ilmuilmu dasar tersebut adalah laboratorium-laboratorium yang terdapat pada fakultas ilmu keolahragaan. Dengan mengembangkan laboratorium diharapkan dapat terjadi peningkatan dalam hal: (1) penyelenggarakan pendidikan akademik, (2) pengembangan ilmu keolahragaan serta (3) pengabdiannya kepada masyarakat dengan jalan menghasilkan karyakarya di bidang ilmu keolahragaan yang diperlukan masyarakat.

Pada dasarnya, laboratorium merupakan fasilitas yang menyediakan peralatan untuk penelitian ilmiah dan pengukuran. Sementara ini semua laboratorium ilmu dasar di FIK UNY masih memfokuskan diri pada fungsinya sebagai sarana penunjang proses pembelajaran. Laboratorium ilmu dasar yang sudah banyak dikembangkan oleh fakultas ilmu keolahragaan di Indonesia adalah biomekanika dan fisiologi latihan. Untuk ilmu dasar rumpun biologi, seperti anatomi, fisiologi dan histologi laboratorium-laboratorium yang ada sering hanya mengacu pada laboratorium pada fakultas kedokteran. Hal ini patut disayangkan mengingat mahasiswa fakultas keolahragaan memiliki kebutuhan yang harus terlayani, yakni arah keilmuan anatomi, fisiologi maupun histologi yang lebih berorientasi pada sistem lokomotorik, bersifat aplikatif dan kontekstual.

Pada perkembangannya, laboratorium berperan sebagai unsur penunjang untuk: (1) proses pembelajaran, (2) proses pengembangan keilmuan yang merupakan wadah kegiatan kelompok dosen dalam bidang minat pengembangan ilmu dan lintas ilmu dan (3) proses pelayanan kepada masyarakat. Sementara ini manfaat laboratorium ilmu dasar rumpun biologi di FIK UNY terutama adalah sebagai sarana pembelajaran agar mahasiswa lebih mendapatkan gambaran tentang objek dari ilmu yang sedang dipelajari. Makna dan kegunaanya laboratorium dalam proses pembelajaran sangat tinggi untuk membekali pengalaman-pengalaman praktis. Pada laboratorium anatomi, fisiologi, dan histologi mahasiswa dapat melakukan berbagai hal, seperti: (1) percobaan-percobaan alat, (2) simulasi kedaan lingkungan yang spesifik, dan (3) pengamatan pada preparat atau tulang manusia, sehingga akan membantu meningkatkan pemahaman atas teori yang telah dipelajari. 
Anatomi adalah ilmu yang mempelajari tentang struktur tubuh manusia, berasal dari bahasa Yunani ana yang berarti habis atau ke atas dan tomos berarti memotong atau mengiris. Maksudnya anatomi adalah ilmu yang mempelajari struktur tubuh (manusia) dengan cara menguraikan tubuh (manusia) menjadi bagian-bagian yang lebih kecil sampai kebagian yang paling kecil, dengan cara memotong atau mengiris tubuh (manusia) kemudian diangkat, dipelajari, dan diperiksa dengan menggunakan mikroskop.

Pembelajaran di laboratorium anatomi FIK-UNY yang diajarkan untuk memperdalam atau memahami ilmu gerak (olahraga) adalah anatomi macroscopia yang tergolong dalam anatomi systematica yang meliputi: osteologi, myologi, arthrologi dan anatomi regionale. Anatomi regionale meliputi regio membri superioris (anggota gerak atas), regio membri inferioris (anggota gerak bawah), regio thoracalis dan regio abdominalis. (Tim anatomi, 2004:1).

Fisiologi merupakan ilmu yang memepelajari fungsi sistem-sistem organ dalam tubuh. Di FIK UNY mata kuliah fisiologi dikembangkan lebih lanjut menjadi fisiologi latihan yang membahas respon fisiologis tubuh manusia yang terjadi pada saat latihan atau olahraga. Tujuan dari perkuliahan adalah agar mahasiswa memahami respon fisiologis tubuh terhadap latihan atau olahraga. Pada akhirnya diharapkan agar mahasiswa mampu mengaplikasikan pengetahuannya, sehingga memberi dasar bagi aplikasi olahraga untuk kepentingan klinis. Ahli fisiologi latihan dapat mengembangkan ilmunya secara klinis misalkan menjadi spesialist pada rehabilitasi gangguan jantung, ahli fisiologi pada keadaan lingkungan spesifik, program exercise testing, programer latihan untuk atlet dan programer latihan untuk mencegah terjadinya gangguan degeneratif.

Mengingat betapa besarnya peran pengetahuan fisiologi bagi peningkatan kebugaran dan pencegahan penyakit, perlu senantiasa dilakukan pengembangan. Pengembangan keilmuan fisiologi terutama dilakukan dalam wadah laboratorium Fisiologi. Laboratorium Fisiologi FIK UNY telah banyak ditunjang oleh fasilitas-fasilitas penelitian maupun pengembangan. Beberapa alat yang sudah dimiliki berupa ergometer gycle, ergometer treadmill, sphyrometer, electrocardiogram dan lactate analyzers. Alat alat ini sudah cukup memenuhi standard akan tetapi selama ini keberadaan alat belum ditunjang oleh manajemen penggunaan dan penyimpanan yang baik. Oleh karenanya sasaran utama sebelum dilakukannya pengembangan laboratorium lebih lanjut adalah dengan meningkatkan mutu pengelolaan alat serta peningkatan sumber daya manusia, sehingga penggunaan fasilitas yang berada di laboratorium Fisiologi FIK-UNY dapat lebih optimal. (Tim Fisiologi, 2002:1-2)

Istilah histologi berasal dari bahasa Yunani bistos yang artinya jaringan dan logia yang berarti ilmu atau pengetahuan, sehingga secara harfiah histologi berarti ilmu yang mempelajari tentang jaringan. Seiring dengan perkembangan teknologi, dewasa ini ruang lingkup histologi tidak hanya terbatas pada tingkat jaringan saja tapi meluas pada struktur mikroskopis makhluk hidup. Pengetahuan tentang struktur makhluk hidup sangat penting untuk mendasari pemahaman fisiologis karena berdasarkan karakteristik struktur, kita dapat meramalkan fungsi dari struktur tersebut. (Tim Histologi, 2006:1) 
Laboratorium Histologi di FIK-UNY merupakan pusat pengembangan dan pembelajaran mata kuliah histologi. Peran laboratorium histologi dalam beberapa tahun terakhir semakin meningkat dengan perubahan status mata kuliah Histologi yang semula merupakan mata kuliah jurusan meningkat menjadi mata kuliah wajib di tingkat fakultas. Untuk mengembangkan dan mengoptimalkan proses pembelajaran mata kuliah histologi, Laboratorium Histologi FIK UNY telah melakukan beberapa perbaikan agar dapat memenuhi peningkatan kebutuhan mahasiswa. Inovasi mendasar yang dilakukan Laboratorim Histologi FIK UNY sementara ini adalah mengubah metode pembelajaran yang semula mengandalkan mikroskop dan slide diganti dengan pembelajaran dengan media komputer.

\section{METODE PENELITIAN}

\section{A. Desain dan Metode Penelitian}

Penelitian ini merupakan penelitian kualitatif. Jenis penelitian ini dipilih untuk melengkapi beberapa penelitian pengembangan laboratorium yang sebelumnya berupa penelitian kuantitatif. Penelitian kualitatif ini diharapkan dapat memberikan gambaran tentang persepsi mahasiswa dan dosen tentang tingkat penggunaan sarana laboratorium serta arah pengembangan laboratorium yang mereka harapkan. Metode pengumpulan data kualitatif yang dipergunakan adalah metode wawancara yang terdiri atas: (1) Focus group discusion (FGD) pada kelompok mahasiswa (5-8 orang/kelompok), (2) In-depth interview pada pengelola laboratorium, dan (3) Observasi non-participant pada setting laboratorium.

\section{B. Populasi dan Sampel}

Populasi penelitian ini adalah seluruh mahasiswa semester ganjil yang mengambil mata kuliah Anatomi, Histologi, dan Fisiologi. Jumlah sampel didasarkan pada saturasi tema pada focus group discussion maupun in-depth interview. Pemilihan sampel pada mahasiswa dilakukan berdasarkan teknik convenience sampling sedangkan pada in-depth interview dengan pengelola laboratorium dengan mempergunakan teknik criterion sampling. Pengelola laboratorium yang diwawancarai adalah kepala laboratarium dan orang yang dianggap berperan dalam menentukan arah perkembangan laboratorium.

\section{Instrumen Penelitian}

Pada penelitian kualitatif, instrumen penelitian adalah peneliti itu sendiri yang dalam hal ini dibantu dengan daftar tema (theme list) yang telah disiapkan. Daftar tema tersebut dipersiapkan oleh tim peneliti sebelum pelaksanaan FGD dan indepth interview dan akan dikombinasikan dengan tema yang terbentuk selama proses FGD maupun in-depth interview. Data pada FGD dan in-depth interview direkam dengan memepergunakan audio tape kemudian ditranskrip. Data hasil 
observasi pada observasi non-participant dicatat dalam catatan lapangan (fieldnotes)

\section{Analisis Data}

Proses pertama analisis adalah data reduction dimana hasil transkrip data FGD dan interiview serta catatan lapangan pada observasi direduksi kemudian dipilah berdasarkan daftar tema awal dan tema yang muncul pada saat pengambilan data. Proses selanjutnya adalah data reconstruction dan analisis thematic. Analisis thematic dilakukan dengan berulang kali membaca hasil transkrip, membandingkan dan mengkontraskan data yang diperoleh dari semua responden pada satu tema dan antar tema dengan memepergunakan bubbling technique. Pada tahap akhir ditarik kesimpulan terakhir tentang bagaimana hubungan antara satu tema dengan tema yang lain pada keseluruhan responden serta inventarisasi semua temuan-temuan penting.

\section{HASIL PENELITIAN DAN PEMBAHASAN}

\section{A. Hasil Penelitian FGD Persepsi Mahasiswa tentang Laboratorium Anatomi, Fisiologi dan Histologi.}

FGD dilakukan pada dua kelompok, masing-masing beranggotakan 6 orang. FGD pada kelompok I dilakukan pada tanggal 18 Juni 2008, sedangkan FGD pada Kelompok II dilakukan pada tanggal 22 Juni 2008. FGD pada masing-masing kelompok dilakukan kurang lebih selama 30 menit. FGD dilakukan pada ruang Laboratorium Anatomi, Fisiologi dan Histologi. Pada awal FGD, fasilitator mengemukakan bahwa identitas semua responden dilindungi dan responden diharapkan dapat secara bebas menyampaikan apa pendapatnya. Pada tiap kelompok diusahakan terdiri atas dua mahasiswa wanita dan dua mahasiswa pria. FGD dilakukan pada dua kelompok karena ditemukan pada kelompok ke-2 tidak ditemukan tema-tema baru, sehingga disimpulkan sudah terdapat saturasi tema. Rentang usia adalah 20 sampai dengan 22 tahun. Kedua kelompok sudah mengikuti mata kuliah Anatomi, Fisiologi, dan Histologi.

Teknik tema FGD dilakukan dengan tema terstruktur akan tetapi responden diperbolehkan untuk menambahkan tem-tema lain yang dianggap penting, relevan dan ingin diungkapkan berkaitan dengan laboratorium Anatomi, Fisiologi dan Histologi. Butir-butir temuan pada saat dilakukan FGD pada kedua kelompok meliputi:

\section{Persepsi Mahasiswa terhadap Praktikum Anatomi, Fisiologi, dan Histologi.}

Mahasiswa merasa bahwa praktikum Anatomi, Fisiologi, dan Histologi sangat bermanfaat. Mahasiswa mengemukakan bahwa Anatomi, Fisiologi, dan Histologi 
sangat menarik karena mengupas tentang manusia. Mahasiswa mengemukakan bahwa praktikum Anatomi, Fisiologi, dan Histologi membantu untuk lebih memahami tentang materi matakuliah Anatomi, Fisiologi, dan Histologi. Beberapa pernyataan antara lain:

Responden D pada kelompok I menyatakan:

“....saya suka matakuliah kaya Anatomi, Fisiologi, dan Histologi pokoknya yang berhubungan sama kesehatan, pengen sih tahu lebih banyak tentang yang seperti itu......."

Responden B dari Kelompok II mengungkapkan hal yang senada:

“ .........kalo saya perhatikan saya sangat tertarik , karena Anatomi, Fisiologi dan Histologi manusia sangat mengupas diri kita,......."

Di sisi lain, mereka juga menyatakan bahwa mahasiswa mengalami kesulitan untuk memahami materi pada mata kuliah Anatomi, Fisiologi dan Histologi karena keterbatasan pengetahuan awal, ketiadaan buku-buku penunjang dan kurang mendapatkan pembimbingan maksimal dari dosen pengampu. Menanggapi sebagian besar dosen yang menuntut mahasiswa belajar secara aktif dan mandiri, sebagian dari mahasiswa yang berasal dari latar belakang SMA noneksakta merasa kesulitan untuk langsung memahami materi-materi yang dibebankan, tetapi sebagian dari mahasiswa yang berasal dari latar belakang SMA eksakta (IPA) merasa bisa untuk memenuhi tuntutan praktikum, seperti yang diungkapkan responden $\mathrm{C}$ pada kelompok I:

“..........praktikum itu menambah pemahaman, waktu teori kita kan masih samar-samar, setelah kita dapat praktikum kita jadi lebih paham, tapi ya tidak paham seluruhnya, tapi sedikit lebih paham, begitu........"

\section{Persepsi Mahasiswa tentang Fasilitas-fasilitas pada Laboratorium Anatomi, Fisiologi, dan Histologi}

Sebagian besar mahasiswa menyatakan bahwa pada umumnya alat-alat yang ada pada laboratarium Anatomi, Fisiologi dan Histologi memadai secara kualitatif. Namun, mahasiswa menyatakan bahwa secara kuantitas sering kurang memadai. Mereka juga mengeluhkan penataan alat serta ruangan laboratorium yang masih berbaur dengan laboratorium lain. Hal ini antara lain dinyatakan oleh responden D pada kelompok I:

“..........menurut saya sarana-sarana yang ada sudah lengkap tapi penataannya kurang rapi, kalau lebih rapi kita juga belajarnya lebih enak, lebih teratur, kalau sekarang ada bangku ditengah-tengah, jadi ribet, menurut saya lebih baik dibuat seperti lab saja, dan kalau ada lemari kan alatnya lebih rapi dan terawat tidak cepat rusak.

Beberapa alat yang dikeluhkan mahasiswa adalah spyrometer, tensimeter, termometer, dan tulang sudah rapuh yang dipergunakan untuk praktik Anatomi, Fisiologi dan Histologi. Untuk spirometer mereka menyatakan bahwa indikator 
penunjuk hasil kurang jelas, seperti yang diungkapkan F pada kelompok II:

“..........Menambahi untuk kapasitas vital. Ada indikator-indikator lepas, pas minta petugasnya dibilang pakai yang sudah ada saja, padahal sudah tidak jelas sama sekali, jadi akhirnya kita manipulasi hasil dari teman yang sudah praktikum....."

Adapún untuk tensimeter mahasiswa mengeluhkan perbedaan hasil yang begitu besar yang ditemukan pada saat mengukur tekanan darah dengan menggunakan tensimeter raksa dan tensimeter digital.

\section{Persepsi Mahasiswa tentang Penggunaan Alat pada Laboratorium Anatomi, Fisiologi dan Histologi}

Sebagian besar mahasiswa menyatakan tidak mengetahui pasti alat-alat apa saja yang dimiliki laboratorium anatomi, fisiologi, dan histologi, mengingat alatalat laboratorium anatomi, fisiologi dan histologi banyak yang ditempatkan di ruang penyimpanan dan tidak dapat diakses mahasiswa. Salah satu diantaranya yakni F pada kelompok I:

“..........sebenarnya timbul pertanyaan yang sejak semester 2 kenapa alatalat yang dipakai untuk praktikum kondisinya tidak sebaik yang digunakan untuk dosen.......",

Responden $\mathrm{F}$ juga menyatakan keluhannya pada prosedur peminjaman alat yang berbelit-belit.

\section{B. Pembahasan}

Mahasiswa FIK UNY merasa bahwa praktikum anatomi, fisiologi, dan histologi sangat bermanfaat. Mereka mengemukakan bahwa anatomi, fisiologi, dan histologi sangat menarik karena mengupas tentang manusia. Pembelajaran di laboratorium anatomi FIK-UNY yang diajarkan untuk memperdalam atau memahami ilmu gerak (olahraga) adalah anatomi macroscopia yang tergolong dalam anatomi systematica yang meliputi: osteologi, myologi, artbrologi dan anatomi regionale. Anatomi regionale meliputi regio membri superioris (anggota gerak atas), regio membri inferioris (anggota gerak bawah), regio thoracalis dan regio abdominalis. (Tim anatomi, 2004:1). Pembelajaran Fisiologi betapa besarnya peran pengetahuan bagi peningkatan kebugaran dan pencegahan penyakit, perlu senantiasa dilakukan pengembangan yang sesuai dengan ilmu yang diperoleh untuk menganalisis di lapangan pekerjaan.sedangkan untuk matakuliah proses pembelajaran mata kuliah histologi, Laboratorium Histologi FIK UNY telah melakukan beberapa perbaikan agar dapat memenuhi peningkatan kebutuhan mahasiswa. Inovasi mendasar yang dilakukan Laboratorim Histologi FIK UNY sementara ini adalah mengubah metode pembelajaran yang semula mengandalkan mikroskop dan slide diganti dengan pembelajaran dengan media komputer. 
Mahasiswa FIK mengemukakan bahwa praktikum Anatomi, Fisiologi, dan Histologi membantu mereka untuk lebih memahami tentang Materi Anatomi, Fisiologi, dan Histologi. Sebagian besar mahasiswa kesulitan untuk memahami materi pada kuliah Anatomi, Fisiologi dan Histologi karena keterbatasan pengetahuan awal, ketiadaan buku-buku penunjang dan kurang mendapatkan pembimbingan maksimal dari dosen pengampu, dikarenakan berasal dari latar belakang SMA non-eksakta merasa kesulitan untuk langsung memahami materimateri yang dibebankan. Sebagian besar mahasiswa menyatakan bahwa pada umumnya alat-alat yang ada pada laboratarium Anatomi, Fisiologi, dan Histologi memadai secara kuailitatif. Namun, mereka menyatakan bahwa secara kuantitas sering kurang memadai. Mahasiswa juga mengeluhkan penataan alat serta ruangan laboratorium yang masih berbaur dengan laboratorium lain.

\section{KESIMPULAN}

Mahasiswa FIK menyatakan bahwa mata kuliah dan praktikum Anatomi, Fisiologi dan Histologi sangat bermanfaat. Walaupun sebagian mahasiswa masih mengalami kesulitan untuk memahami materi kuliah dan praktikum dikarenakan bekal yang dirasakan belum mencukupi. Hal yang selanjutnya dikeluhakan adalah manajemen alat-alat Anatomi, Fisiologi dan Histologi yang dipersepsikan belum terorganisir dengan baik. Sesuai dengan mahasiswa, pengelola juga merasakan adanya kendala pada fasilitas-fasilitas yang ada. Walaupun demikian pengelola lebih dapat memahami bahwa keadaan tersebut terutama disebabkan oleh jumlah mahasiswa yang terus bertambah, sedangkan fasilitas yang dimiliki tidak mengalami peningkatan yang berarti. Walaupun demikian terdapat perbedaan persepsi antara pengelola dengan mahasiswa mengenai optimalisasi fasilitas yang ada pada laboratorium Anatomi, Fisiologi, dan Histologi. Pengelola menyatakan bahwa secara garis besar penggunaan peralatan pada laboratorium Anatomi, Fisiologi, dan Histologi sudah cukup memadai.

\section{SARAN}

Berdasarkan hasil yang dibahas dalam penelitian dan kesimpulan tersebut di atas, maka peneliti memberikan beberapa saran sebagai berikut:

1. Dengan adanya persepsi mahasiswa tentang optimalisasi dan arah pengembangan laboratorium Anatomi, Fisiologi, dan Histologi dapat meningkatkann evaluasi proses pembelajaran khususnya pada praktik.

2. Disarankan untuk para dosen dan pengelola laboratorium, agar dapat memperhatikan dan meningkatkan proses pengajaran, sehingga dapat bermanfaat terhadap mahasiswa yang pengalaman materi pada waktu di SMA belum banyak yang diperoleh khususnya dari jurusan IPS. 
3. Kelemahan dalam penelitian ini hanya terdapat satu variabel yaitu Persepsi mahasiswa, sehingga masih diperlukan penelitian lebih lanjut dengan menambah variabel yang berhubungan dengan pemakai laboratorium, seperti dosen pengampu dan pengelola laboratorium.

\section{DAFTAR PUSTAKA}

http://www.suaramerdeka.com/harian/0312/31/ora7.htm. online 8 April 2008.

Tim Anatomi. (2004). Diktat Anatomi Manusia. Yogyakarta: Laboratorium Anatomi FIK-UNY.

Tim Fisiologi. (2002). Petunjuk Praktikum Fisiologi. Yogyakart: Laboratorium Fisiologi FIK-UNY.

Tim Histologi. (2005). Diktat Histologi. Yogyakarta. Laboratorium Histologi FIK UNY. 